\title{
All Pharmacotherapy Prescriptions
}

National Cancer Institute

\section{Source}

National Cancer Institute. All Pharmacotherapy Prescriptions. NCI Thesaurus. Code

C128532.

Any prescription or order associated with a given course of treatment; a new prescription or order or the continuation of an existing prescription or order. 